\title{
Tiquinho e Abel no abismo da solidão: homoerotismo e absolvição em João Silvério Trevisan
}

\author{
Samuel Lima da Silva*
}

\section{A absolvição pela memória: o anjo e o pupilo}

Na obra Em nome do Desejo (1985), do paulista João Silvério Trevisan, a memória assume o delineio principal desse operador simbólico (a absolvição) na economia interna do texto. A memória é, na narrativa, o canal para que o personagem possa desenvolver o anseio por uma redenção referente à sua relação amorosa com Abel. Tiquinho necessita urgentemente de uma libertação das amarras do passado amoroso, fazendo, com o seu regresso ao seminário, uma confissão, mais precisamente, um ritual de cura. Olhando-se frente ao crânio, o que o narrador projeta é uma dinâmica consigo mesmo (e com o leitor) no intuito de expurgar os demônios que o habitam.

Desde o primeiro momento, mesmo antes de a narrativa passar a ser emoldurada pelo formato catequista de confissão, o narrador padece, aos quarenta anos de idade, das mazelas que esse relacionamento amoroso lhe deixou. O homoerotismo é tecido por meio da memória afetiva, singular, que transforma o personagem em um indivíduo encarcerado em si mesmo. Memória e erotismo acabam, portanto, por constituir o canal pelo qual a absolvição ocorre no romance.

Nesta pesquisa, o termo absolvição, originário do latim absolutio, é empregado em sentido etimológico, compatível com o seu significado referente à religião. Em consonância com o dicionário teológico enciclopédico, o termo absolvição aparece descrito como:

Na práxis do sacramento da penitência, a absolvição é sentença pronunciada pelo sacerdote competente (que tem a faculdade) para conceder a remissão dos pecados. É, pois, uma palavra eficaz de perdão e de reconciliação, que leva a bom termo o itinerário penitencial do pecador (LEXICON, 2003, p. 3).

Pós-doutorando em Estudos Literários na Universidade do Estado de Mato Grosso (UNEMAT), Mato Grosso, Brasil. E-mail: samuellds@live.com. 
A citação supratranscrita refere-se basicamente ao campo semântico religioso, embora saibamos que a questão da absolvição percorre também o universo jurídico, além de outras áreas do conhecimento. No presente estudo, compreendemos a absolvição como um elemento central para o narrador do romance, haja vista que há o empreendimento de um retorno ao passado, em uma tentativa de redenção operada pelo viés memorialístico-homoerótico. É por meio da dor da ausência daquele Outro que se amou, que Tiquinho regressa ao passado, reconstruindo muros desabados, relembrando a experiência longínqua do primeiro amor.

O desejo do protagonista em receber uma absolvição ocorre, funcionalmente, desde o início do romance, momento em que o personagem, já adulto, regressa ao seminário para confrontar-se com o seu passado amoroso. Desde a chegada ao atual orfanato, Tiquinho anseia que seus pecados sejam expurgados, e a maneira que encontra para que isso ocorra é regressando ao antigo seminário por meio da memória. A incidência desse desejo de absolvição por parte do narrador pode ser notada, principalmente, pelo fato de ele ainda ser apaixonado por Abel. Tal fato suplanta no personagem um anseio por uma reconstrução do passado, percorrendo novamente os corredores do seminário. Vejamos a primeira manifestação de Tiquinho, referente ao que pode ser percebido como uma necessidade de redenção. O personagem chega ao seminário e passa a ambientar-se no espaço geográfico em que agora se encontra:

Sinto uma espécie de saudade contida. Quem sabe o que pretendo encontrar. Talvez um espaço sagrado, no fundo de mim, que às vezes parece miragem. Ainda assim, sempre existe a possibilidade de descobrir algum tesouro enterrado nestes meus quarenta anos. É inevitável lembrar da mulher de Lot, que virou estátua de sal quando olhou para trás. Vim correr o mesmo risco. O que haveria lá no fundo, depois da fumaça? (Trevisan, 2001, p. 15).

O regresso do personagem ao antigo seminário é a primeira manifestação de sua vontade por uma absolvição extremamente necessária ao seu íntimo. O personagem sente-se culpado por não ter conseguido levar adiante seu relacionamento amoroso com Abel, precisando expurgar, de alguma forma, toda a angústia e aflição que o corrompe. Quando lemos "sinto uma espécie de saudade contida" e "quem sabe o que pretendo encontrar", é possível entrevermos o estado de desolação em que o narrador se encontra. Este narrador tem ciência do que o espera ao reconstruir os muros do passado e reerguer seu pretérito amoroso. A fumaça que o atormenta até os dias atuais precisa ser dissipada, anulada, engendrando uma libertação para o personagem.

A carne, o desejo dos corpos e a ardência do ato sexual parecem ser um dos principais elementos que corroboram a manifestação da ânsia por absolvição em Tiquinho. Contudo, não unicamente a questão do desejo sexual, mas algo mais 
profundo, mais intenso. Tratamos, nesse enquadramento, da questão da experiência interior, isto é, da relação de Tiquinho com aquilo que o cerca, mais especificamente, de toda a operação simbólica que faz de Tiquinho um sujeito amoroso altamente solitário.

Bataille argumenta sobre a questão da experiência interior, afirmando que o erotismo é "um desequilíbrio em que o próprio ser se coloca em questão, conscientemente. Em certo sentido, o ser se perde objetivamente, mas então o sujeito se identifica com o objeto que se perde. Se for preciso, posso dizer, no erotismo: eu me perco" (BATAILLE, 2013, p. 55). A experiência pela qual Tiquinho passa é algo de que não mais consegue se libertar, fazendo com que as feridas amorosas ainda latejem em sua pele.

Na passagem supratranscrita, Bataille aborda a questão do erotismo fortemente atrelado a uma espécie de desnorteamento do sujeito. Há um desequilíbrio entre o indivíduo e o objeto desejado, tornando a atração erótica uma balança, em que ambos os lados estão suspensos, mas apenas um lado é menos imponente. Na diegese de Em nome do desejo, esse desequilíbrio pode ser percebido na figura de Tiquinho, sendo o homoerotismo aquilo que calibra os dois personagens. A experiência exterior do narrador (a realidade opressora do seminário) não diminui a experiência interior do personagem, pois Tiquinho vivencia a experiência homoerótica de maneira muito mais intensa que Abel. É justamente nele que está centrada toda a carga sentimental que o romance desvela.

Em determinado momento, Tiquinho confronta-se consigo mesmo, já demonstrando o sofrimento por qual passa, dando os principais indícios de que não suporta mais o peso da vida:

\begin{abstract}
Por todos esses anos vim aprendendo a driblar o sofrimento e hoje sou capaz de sorrir como se portasse nos lábios um permanente anúncio de creme dental. Ontem tomei um pileque, mais um. Não tenho ideia de onde passei a noite. Num clube noturno, num motel, numa casa de massagem? De manhã fiz um telefonema e saí de carro. Pela estrada, ia feliz. Só parei diante deste casarão, onde pressinto vagamente que venho à procura de um elemento primordial (Trevisan, 2001, p. 15-16, grifo nosso).
\end{abstract}

Nesta citação, podemos notar não apenas a aflição do personagem, mas também a principal marca do desejo de absolvição sentido pelo protagonista. Tiquinho, pouco depois de entrar no espaço geográfico do antigo seminário, já tem conhecimento de que será necessária uma busca em suas memórias para, tal como o próprio personagem afirma, encontrar "um elemento primordial" de sua existência. Esse elemento primordial pode ser percebido em duas instâncias: a de um possível reencontro com Abel e a libertação dos pecados do passado. Em determinado momento, antes de iniciar seu rito de confissão, o personagem declara: "não posso dormir. Recuso a velha paz. Sensações estranhas me invadem neste 
local habitado por meus fantasmas. Quem são esses que forçam a minha porta?" (TrevisAn, 2001, p. 17). O estado de aflição do narrador o leva a desembocar em um diálogo consigo mesmo, reencontrando Abel por meio de suas lembranças.

Ainda com base em Bataille, verificamos que a experiência interior pela qual o personagem passa atrela-se à memória de forma a potencializar o discurso do romance, presentificando uma estética da absolvição, um discurso que almeja redenção. O autor esclarece que:

Tratando-se do erotismo (ou de religião), sua experiência interior lúcida era impossível num tempo em que não despontava claramente o jogo de equilíbrio do interdito e da transgressão, que ordena a possibilidade de ambos. Mas é insuficiente saber que esse jogo existe. O conhecimento do erotismo, ou da religião, exige uma experiência pessoal, igual e contraditória, do interdito e da transgressão (BATAILle, 2013, p. 59).

O jogo entre interdito e transgressão pode ser compreendido como uma experiência pessoal que assola o indivíduo, fazendo dele algo vinculado intimamente às intempéries sociais. $\mathrm{O}$ conhecimento da experiência e da religião a que Bataille alude pode estar presentificado, em Em nome do desejo, na jornada empreendida por Tiquinho em conhecer a si próprio, vivenciando a religião cujas amarras o prendiam. O personagem percorre caminhos tortuosos da alma e do coração, em um percurso de autoconhecimento tanto do corpo quanto do Outro que ele ama. Quando Bataille afirma que o conhecimento do erotismo ou da religião exige uma experiência pessoal referente ao interdito e à transgressão, percebemos em Tiquinho não apenas o desejo por redenção, mas, também, o desejo homoerótico completamente enviesado para a transgressão às normas vigentes.

É importante que, nesse processo analítico, voltemo-nos à teoria de Paul Ricoeur (2007) sobre a memória, pois o autor trabalha com um tipo específico de argumentação sobre esse tema, o qual nos ajuda a perceber algumas questões no romance escrito por Trevisan. Em seu livro intitulado A memória, a história e o esquecimento, o autor esclarece a diferença entre memorização e rememoração:

Com a rememoração, enfatiza-se o retorno à consciência despertada de um acontecimento reconhecido como tendo ocorrido antes do momento em que esta declara tê-lo sentido, percebido, sabido. A marca temporal do antes constitui, assim, o traço distintivo da recordação, sob a dupla forma da evocação simples e do reconhecimento que conclui o processo de recordação. A memorização, em contrapartida, consiste em maneiras de aprender que encerram saberes, habilidades, poder-fazer, de tal modo que estes sejam fixados, que permaneçam disponíveis para uma efetuação, marcada do ponto de vista fenomenológico por um sentimento de facilidade, de desembaraço, de espontaneidade (RICOEUR, 2007, p. 73). 
Ricoeur distingue, de maneira sintomática, a diferença entre os dois conceitos, deixando em evidência que ambos operam uma sistematização do elemento memorialístico, mas que possuem diferenças estruturais que o diferenciam. Na obra Em nome do desejo, o que parece presentificado na narrativa é justamente a rememoração, pois o narrador concede importância para uma "consciência despertada de um acontecimento reconhecido", como o próprio Ricoeur afirma. Há, no romance, a marca temporal do passado, que vai, de forma progressiva, costurando as recordações, em uma espécie de evocação do passado, de retorno a uma lembrança, ou seja, uma consciência que, ainda no presente, causa sensações no personagem.

A rememoração que está em circuito no romance de Trevisan se encontra intimamente atrelada ao discurso amoroso presente em toda a trama. Tiquinho empreende um discurso que eleva a lembrança ao estatuto da dor, engendrando uma melancolia que o exaspera, mas, que, em seu íntimo, necessita de uma absolvição pelas falhas cometidas no passado. É por meio do ato memorialístico que o personagem consegue uma possível reparação pelo erro cometido com Abel.

A estética da absolvição no romance em questão tem seu introito, efetivamente, na culpa sentida por Tiquinho em decorrência do plano por ele arquitetado para "castigar" o amado, Abel. O narrador afirma que Abel não demonstrava mais sentimento amoroso por ele, ampliando um campo de rejeição que afetava profundamente o personagem. É por meio da vingança arquitetada por Tiquinho que o personagem padecerá de uma culpa extremamente dolorosa; curiosamente, é esse erro que deflagra todo o processo de angústia que assola o personagem pelos anos seguintes. É pela dor da rejeição amorosa que Tiquinho enxerga, na vingança, uma maneira de dar a Abel aquilo que é tido como ato reparador. Vejamos, partindo desse ponto analítico, como se dá o fator de indução ao desejo de absolvição por Tiquinho, percebendo as idiossincrasias que percorrem essa questão:

Teve desejos de punir esse anjo rebelde?

- Dali por diante, Tiquinho entregou-se totalmente à tarefa da vingança. Aquele amor que tinham vivido era radical demais para se deixar perder sem uma reação contrária, em igual intensidade. Queria punir, ferozmente, calculadamente. Como um Deus inflexível e sábio.

Que castigo mereciam os anjos rebeldes?

- Mereciam a expulsão do céu e a condenação ao inferno. Foi o que Tiquinho decidiu. Bastava aguardar a oportunidade certa (TrevisAN, 2001, p. 216).

Como percebido na citação supratranscrita, a ideia de vingança em relação a Abel é delineada em moldes religiosos, da mesma forma como quase tudo no romance. Tiquinho se encontra tão absorto por esse universo, de maneira a não desvencilhar seu pensamento dessa conjectura cristã potencialmente corrosiva. Quando decide vingar-se de Abel, o personagem toma tal empreitada como uma missão divina, sendo o amado o alvo do castigo, mais precisamente, de sua ira. 
Em estudo sobre Em nome do desejo, os pesquisadores Maria de Fátima Lopes Vieira Falcão e Fábio Camargo afirmam que "o mistério da paixão de Tiquinho culminará com uma forte transformação de seu caráter, um garoto tímido [...] como diz o narrador, para lidar com a vingança e o remorso, dois sentimentos febris, de uma vez só. São fases que Tiquinho teve de passar na sua via dolorosa para se individualizar" (FALCÃo, CAMARGO, 2015, p. 183). Percebe-se que o percurso que Tiquinho percorre, desde a entrada de Abel no seminário, está atrelado a um processo de construção de identidade, de descoberta tanto do sexo como do corpo. A vingança que o personagem arquiteta, mesmo tendo fortes proporções, ajuda na construção identitária do personagem. Ainda na esteira de Ricoeur, apontamos sua observação acerca da questão da lembrança enquanto potência da imagem:

Enquanto a imaginação pode jogar com entidades fictícias, quando ela não representa o real, mas se exila dele, as lembranças colocam as coisas do passado; enquanto o representado tem ainda um pé na apresentação enquanto apresentação indireta, a ficção e o fingido situam-se radicalmente fora de apresentação (RICOEUR, 2007, p. 64).

É preciso perceber que a lembrança, em Trevisan, não funciona como um mero instrumento narrativo, mas como um operador simbólico que auxilia o personagem na reestruturação de seu passado. Quando lemos "as lembranças colocam as coisas do passado", percebemos, com efeito, a prosa trevisaniana, sobretudo no que concerne ao ritual memorialístico de Tiquinho, como um discurso que opera essa situação de forma acabada, isto é, enxergando o passado como algo impossível de ser mudado. No entanto, é por meio dessa impossibilidade temporal que o personagem responde às perguntas de seu duplo, pois é nesse ritual de exposição de suas lembranças que o personagem encontra um modo de se absolver dos erros cometidos no período em que era um seminarista.

A vingança contra Abel é sabiamente planejada na mente de Tiquinho, que elabora um plano do qual o antagonista não possa sair incólume. Tiquinho resolve agir em uma noite em que falta energia elétrica no seminário, fato este que causa um enorme alvoroço naquele espaço geográfico: "os seminaristas gritavam e corriam por todos os recantos da casa, batendo portas e janelas. Muitos concentravam-se nos lavatórios, abrindo todas as torneiras e atirando água uns nos outros" (TrevisAn, 2001, p. 216). A agitação tomara conta por completo do seminário, fazendo do espaço um local de desordem e descontrole. Em determinado momento, "alguém resolveu tirar a roupa. Aquele foi o sinal que bastou. Em alguns minutos, corpos pelados circulavam por entre as camas ou saltavam sobre os colchões, como num grande e alucinado circo" (Trevisan, 2001, p. 217). Em meio àquela confusão generalizada, a lanterna de um dos prefeitos da disciplina foi roubada de suas mãos pelos seminaristas, a fim de ser utilizada nas brincadeiras dos alunos. O narrador descreve tal confusão como "a memória jamais esqueceria aquele espetáculo impensável numa instituição onde se formavam os eleitos do Senhor" (Trevisan, 2001, p. 217). 
Durante o processo de histeria ocorrida no seminário, Tiquinho permanecia calmo, não fazendo parte de todo o circuito caótico que ali se apresentava. Mas, em um determinado momento, quando um segundo prefeito de disciplina entrara no recinto munido de outra lanterna, Tiquinho vê, nesse instante, aquilo de que precisava para vingar-se de Abel:

Bem de acordo com a loucura geral, apossou-se da lanterna e, com seu foco iluminado, varou toda a extensão do dormitório, à cata de Abel, que já vira entre os corpos nus. Não tardou em localizá-lo sobre uma cama, bem no centro do dormitório, pulando e rodopiando para melhor exibir sua beleza. Tiquinho sentiu na garganta que chegara o momento da vingança. Sorrindo de secreto prazer, não apenas fixou o facho de luz sobre o corpo nu e o rosto de Abel, como passou a persegui-lo desde o momento em que Abel começou a fugir. Então, o espetáculo geral foi se concentrando naquele duelo de luz e sombra, através do qual os presentes puderam comprovar sobejamente como era bonita a bunda de Abel Rebebel e negros os seus pentelhos. Agarrado à lanterna, Tiquinho manteve-se implacável como a rival ensandecida de algum filme de amor. Abel tentou esconder-se e começou a vestir nervosamente o pijama, já que o foco de luz se recusava a abandoná-lo. Pior a emenda: todos puderam testemunhar que, depois de acuado e revelado, Abel Rebebel era vencido por uma luta feroz, maligna, humilhante (TrEviSAN, 2001, p. 218).

Durante todo o instante em que Tiquinho evidencia Abel por meio da luz provinda da lanterna, o personagem vivencia o momento da vingança de maneira permanente, total, conseguindo extrair da situação todo o proveito de que necessitava; no entanto, as feridas e consequências que tal enfrentamento deixariam, não seriam superadas ao longo da existência do jovem vingador. A experiência advinda desse momento faz-nos perceber o narrador como nunca aparecera na narrativa até então; ele agora transfigura em fúria todo o amor sentido por Abel, mais precisamente, em uma espécie de ódio latente à sua vida. Nesse trecho, os aspectos homoeróticos são mesclados à sensação transgressora, por parte do personagem, de deixar Abel à mostra perante todos. Há, aqui, um discurso amoroso revestido de ódio e de amargura, que recobre o protagonista em sua configuração estilística e estrutural. Quando lemos "Abel Rebebel era vencido por uma luta feroz, maligna, humilhante", é possível constatar o implacável anseio de Tiquinho em expor o amado, castigando-o severamente.

A cena final da vingança explode, no narrador, toda a amargura e desolação que o perseguirá em sua vida. O estado pleno de assolação que delineia o personagem é engendrado pela culpa por ter segurado a lanterna e exposto Abel frente aos dirigentes do seminário. Tiquinho sabia das consequências fatais que seriam tomadas com relação a Abel, mas, em seu momento de ira, tais questões não foram postas em primeiro plano. Quando perguntado por seu duplo acerca de um possível arrependimento durante o ato de execução, o personagem responde: "não. Enquanto 
o ardoroso ódio continuou mascarando o amor, a vingança de Tiquinho prosseguiu, planejadamente" (Trevisan, 2001, p. 219).

A percepção da estética da absolvição está atrelada ao nível de amargura experimentada pelo narrador. Tal percepção é sentida mais nitidamente na narrativa realizada pelo Tiquinho maduro, que responde às perguntas de seu duplo. Em termos didáticos, o Tiquinho das memórias sentirá esse sentimento de redenção somente quando descobrir as consequências do acontecido durante a falta de energia no seminário, exatamente na reta final do romance. Pouco depois do ocorrido, Tiquinho, já ciente de que Abel seria severamente punido com a expulsão do seminário, começa a padecer de uma culpa corrosiva que o destrói internamente. "Consumada a vingança, sobrou um panorama de ruínas irremediáveis e puros destroços, bem dentro do coração de Tiquinho. Então chegou a vez do remorso" (TrEvisan, 2001, p. 220).

É preciso delimitar que o ato de vingança de Tiquinho constitui a grande estrutura que calcifica a absolvição no romance. Praticado o ato, o personagem estará entregue a uma eterna busca por remissão de seus erros, trazendo-o de volta ao seminário, quarenta anos depois, em uma tentativa de reconstruir os muros melancólicos da dor de outrora. A maneira que o narrador encontra para obter uma possível libertação é construída por meio da memória, do regresso ao seu passado. Narrar, aqui, é mesclar a memória com o homoerotismo, presentificando uma ideia de absolvição que concede ao personagem um bálsamo para suas feridas. Nessa perspectiva, a figura barthesiana da verdade parece ser a que melhor define a complexa situação que Tiquinho cria para si próprio. Conforme Barthes:

Todo episódio de linguagem relacionado com a "sensação de verdade" que o sujeito experimenta pensando em seu amor, quer acredite ser o único a ver o objeto amado "em sua verdade", quer defina a peculiaridade de sua própria existência como uma verdade a respeito da qual não pode ceder (BARTHEs, 2003, p. 337).

O território da verdade em Em nome do desejo, configura também o território da culpabilidade. A sensação de verdade é precisamente aquilo que move a vingança de Tiquinho, fazendo-o levar adiante seu plano contra Abel. Aqui, percebemos a verdade como uma sensação de obrigatoriedade em rebelar-se contra o objeto amado. Tiquinho acredita em sua própria realidade e, imerso nas contingências amorosas, necessita provar para si mesmo que é capaz de fazer Abel voltar a amálo, tal como fazia em tempos pregressos. Tiquinho experimenta a sensação de verdade com a mesma intensidade que ama seu colega seminarista. Como dito anteriormente, a verdade, em Tiquinho, é um território de indulgência, que se soma ao seu estado de delírio amoroso. Barthes, como supracitado, afirma que a verdade do sujeito amoroso está em enxergar a verdade de outro como algo apreensível e verdadeiro.Após Tiquinho expor o amado, nu, frente a todos, Abel é conduzido a um regime de incomunicabilidade, permanecendo isolado em um quarto nos fundos 
do seminário. Tiquinho tenta de todas as formas conversar com Abel, mas suas tentativas acabam frustradas. O narrador "sofria várias modalidades de dor que só Abel poderia mitigar. Queria matar as saudades dele e pedir-lhe mil vezes perdão. Queria declarar-se apaixonado, escravo e fêmea por toda a eternidade" (TrEvisAn, 2001, p. 221). É a partir desse momento que a desolação passa a ser um componente contínuo na vida do personagem, pois Tiquinho não consegue entrar em contato com Abel antes que este parta do seminário. Findada a reclusão, Abel é levado embora por seus pais, e Tiquinho é separado, de maneira irreversível, de seu amado. O jovem personagem entra em um estado de aflição que o leva a sofrer, inclusive, problemas de saúde, o que o faz, logo depois, ser retirado do seminário, não mais retornando como seminarista; seu regresso ao seminário ocorre já quando adulto.

É na fase adulta que Tiquinho resolve suturar os pontos advindos de suas feridas amorosas. É necessário, portanto, voltar ao espaço de outrora e, por meio da memória, evocar uma absolvição e um reencontro com Abel. Narrando sua história ao duplo, o narrador reergue as altas paredes do seminário, revivendo toda atrajetória de amor com Abel. Na manhã seguinte, após o seu regresso memorialístico ao passado, o personagem acorda, resolve caminhar pelo orfanato e, em determinado momento, ouve de um funcionário que Abel Rebebel o espera no salão de entrada: "na sala de visitas alguém o espera. E avisa que se chama Abel Rebebel” (TrevisAn, 2001, p. 232). Tiquinho segue, de maneira triunfal, em direção à portaria, no entanto, não é oferecido ao leitor uma resposta exata acerca do reencontro entre ambos:

Aquele se arremessa em direção à portaria sou eu, produto de pura paixão. Vou me encontrar com um anjo de grandes asas ondulantes, do lado de fora do paraíso. Se Vingador de Amores ou Esposo Sempiterno, não importa. Agora já estamos trocados. Em breve atingirei meu secreto centro (TrevisAn, 2001, p. 236).

O personagem segue ao encontro de seu amado, na esperança de obter perdão, de fazer-se novamente amado na vida do outro. A absolvição, após o ritual memorialístico, ocorre de maneira quase espiritual. Foi necessário utilizar-se da memória afetiva para trazer Abel de volta à sua verdade, à sua existência. $\mathrm{O}$ desejo de absolvição presentifica-se com o passado resgatado e com a remissão o aguardando em frente do atual seminário. O narrador, em breve, atingirá seu secreto centro, isto é, sua paz de espírito.

\section{Referências}

Barthes, Roland. Fragmentos de um discurso amoroso. Trad.: Márcia Valéria Martinez de Aguiar. São Paulo: Martins Fontes, 2003.

Bataille, Georges. O erotismo. Trad.: Fernando Scheibe. Belo Horizonte: Autêntica, 2013. 
Falcão, Maria de Fátima Lopes Vieira e CAmargo, Flávio Pereira. "Eu amo Abel como a mim mesmo e o amor de Jesus é o mesmo dentro de nós": a dessacralização do divino na obra Em nome do desejo, de João Silvério Trevisan. In: Mitidieri, André Luis; CAmargo, Flávio Pereira (org.). Literatura, homoerotismo e expressões culturais. Ilhéus, Editora da UESC, 2015, p. 165-19o.

LeXICon - dicionário teológico enciclopédico. Trad.: João Paixão Neto e Alda da Anunciação Machado. Edições Loyola, São Paulo, 2003.

Ricoevr, Paul. A memória, a história, o esquecimento. Trad.: Alain François [et al]. Campinas: Editora da UNICAMP, 2007.

Santos, Rick J. PoÉtica da Diferença: um olhar queer. São Paulo: Factash: Hagrado, 2014 .

Trevisan, João Silvério. Em nome do desejo. $3^{\text {a }}$ ed. Rio de Janeiro: Record, 2001.

Recebido em 2 de março de 2020.

Aprovado em 8 de abril de 2021.

\section{Resumo}

Tiquinho e Abel no abismo da solidão: homoerotismo e absolvição em João Silvério Trevisan

\section{Samuel Lima da Silva}

Estudo acerca da configuração estilístico-formal da figura da absolvição, na realidade diegética do romance brasileiro Em nome do desejo (1985), de João Silvério Trevisan. Na trama, o leitor é posto frente a um discurso homoerótico potencializado pela consternação do narrador Tiquinho, personagem esse que se exaspera emocionalmente devido a separação amorosa, bem como pelo descobrimento do corpo, da alma e das encruzilhadas do desejo sexual.

Palavras-chave: absolvição, romance, João Silvério Trevisan, narrador, discurso homoerótico. 